\title{
Leukocyte glutamate dehydrogenase activity in patients with degenerative neurological disorders
}

\author{
D AUBBY, ${ }^{*}$ H K SAGGU, ${ }^{*}$ P JENNER, ${ }^{*} \dagger$ N P QUINN, ${ }^{*} \dagger$ A E HARDING,$\dagger$ \\ C D MARSDEN*†
}

From the MRC Movement Disorders Research Group, University Department of Neurology and Parkinson's Disease Society Research Centre, Institute of Psychiatry \& King's College Hospital Medical School, ${ }^{*}$ and the University Department of Clinical Neurology, Institute of Neurology \& National Hospital for Nervous

Diseases, $\dagger$ London, $U K$

SUMMARY Leukocyte glutamate dehydrogenase (GDH) activity was measured in 39 normal subjects, 32 neurological controls, 66 patients with progressive ataxic disorders, 32 with multiple system atrophy, 40 with Parkinson's disease, eight with Steele-Richardson-Olszewski syndrome, eight with juvenile Parkinsonism and four with the dystonia-Parkinsonism syndrome. GDH activity was reproducible to within $10 \%$ in leukocyte pellets stored at $-70^{\circ} \mathrm{C}$ for up to 9 months, and did not vary with sex or age in control subjects. There was marked variation in the relative proportions of heat stable and heat labile forms of GDH between control subjects and on repeated assay in the same subject. Total leukocyte GDH activity was similar in normal subjects and neurological controls. Mean total GDH activity was reduced in all patient groups by between 15 to $29 \%$ compared with controls. Fourteen patients had total GDH activity below $50 \%$ of the control mean, but low values were not specific for any one disease (five had ataxic disorders, four Parkinson's disease, three multiple system atrophy, one juvenile Parkinsonism, and one dystonia-Parkinsonism). The heat labile fraction of GDH represented about $20 \%$ of total activity in control subjects, and $27 \%$ in the patients with reduced total GDH activity. Thus low GDH activity was not diseasespecific in this study, and the heat-labile GDH fraction was not selectively affected. "Reduced" leucocyte GDH activity in some patients may represent no more than the lower end of a normal distribution.

The aetiology of most degenerative ataxic disorders is unknown, particularly if the onset of symptoms is in adult life. Although late onset cerebellar ataxia is sometimes inherited as an autosomal dominant trait, many patients do not have similarly affected relatives. Clinical evidence of cerebellar dysfunction is the most prominent finding in both familial and isolated cases, but associated features such as dementia, supranuclear ophthalmoplegia, optic atrophy, extrapyramidal involvement and peripheral neuropathy are common. ${ }^{1-3}$ This group of multisystem disorders is often referred to as the olivopontocerebellar atrophies, as degeneration of the inferior olives and pontine nuclei is frequently found at necropsy,

Address for reprint requests: Professor C D Marsden, Department of Clinical Neurology, Institute of Neurology, Queen Square, London WCIN 3BG, UK.

Received 23 December 1987.

Accepted 7 March 1988 together with loss of Purkinje cells and white matter in the cerebellum. This is usually accompanied by degenerative changes in the basal ganglia and spinal cord. 4,5

In 1980, Plaitakis and colleagues ${ }^{6}$ described three adult patients with progressive ataxic disorders who were found to have reduced activity of the enzyme glutamate dehydrogenase (GDH) in leukocytes and skin fibroblasts. About 30 further deficient patients, diagnosed as having olivopontocerebellar atrophy (OPCA) on clinical grounds, have subsequently been described. ${ }^{7-14}$ Their clinical features were somewhat variable, but the commonest presentation comprised a syndrome of cerebellar ataxia and/or Parkinsonism, often accompanied by bulbar palsy, supranuclear ophthalmoplegia, or an axonal peripheral neuropathy. The age of onset of symptoms ranged from 11 to 79 years. About half of the patients had similarly affected relatives, but no consistent pattern of inheritance was observed. 
Total leukocyte GDH activity ranged from 20 to $70 \%$ of mean control values in these cases; the definition of deficiency has tended to be somewhat arbitrary and there has been overlap in levels of enzyme activity between patients and controls. ${ }^{8-10}$ However, Plaitakis et $\boldsymbol{a l}^{\mathbf{1 0}}$ and Konagaya and colleagues $^{14}$ have suggested that there are two GDH isoenzymes, one heat labile and the other heat stable, with virtually undetectable activity in the heat labile fraction in some cases of OPCA. Furthermore, glutamate loading tests were reported to result in higher plasma glutamate concentrations in deficient patients than in controls. ${ }^{15-17}$ These observations could be of functional significance as glutamate is known to be neurotoxic. ${ }^{18}$

This paper reports the results of a study of leukocyte GDH activity in 71 control subjects and 158 patients with degenerative neurological disorders, including 66 with progressive ataxic syndromes and 32 patients with multiple system atrophy. The investigation involved the collection of a large number of blood samples at different times and from a variety of locations. Initially, a number of experiments were performed in order to optimise assay methods and obtain consistent results in assaying total and heat labile/stable leucocyte GDH activity under these conditions. These investigations are described first; the results in patients and control subjects are presented subsequently.

\section{Methods}

\section{GDH ASSAY PROCEDURES}

\section{Basic total GDH enzyme assay}

Total GDH activity was assayed in leukocyte preparations according to a modification of the technique of Duvoisin et $a{ }^{8}{ }^{8}$ Venous blood $(20 \mathrm{ml})$ was collected in a heparinised syringe, mixed with $5.0 \mathrm{ml}$ of $6 \%$ dextran solution, and allowed to stand in the inverted syringe at room temperature for at least 1 hour to allow separation of red blood cells. The supernatant plasma was collected through a bent needle and centrifuged at $4^{\circ} \mathrm{C}$ for $10 \mathrm{~min}$ at $480 \mathrm{~g}$. The resulting leukocyte pellet was suspended in $0.5 \mathrm{ml}$ of isotonic saline $(0.154$ $\mathrm{M} \mathrm{NaC1}$ ) and $7.0 \mathrm{ml}$ of $0.87 \%$ ammonium chloride was added to lyse any erythrocytes trapped in the pellet. After exactly $5 \mathrm{~min}$ the suspension was centrifuged again. The resulting pellet was washed at least twice by resuspension in $20 \mathrm{ml}$ ice-cold isotonic saline and recentrifuged at $480 \mathrm{~g}$ for $10 \mathrm{~min}$. The pellets were then frozen and stored at $-70^{\circ} \mathrm{C}$ for periods of up to 12 months. On the day of assay, the leukocyte pellet was homogenised in $1.0 \mathrm{ml}$ of $0.05 \mathrm{M}$ Trizma base (tris[hydroxymethyl]-aminomethane), $\mathrm{pH} 7 \cdot 4$, using a Teflon glass homogeniser, for $1 \mathrm{~min}$. To the resulting homogenate Triton X-100 was added so as to give a final concentration of $0.15 \%$.

In a preliminary series of studies leukocyte pellets were prepared from four different individuals and GDH activity assayed in the absence of Triton X-100 and in the presence of a range of concentrations of Triton X-100 between
$0.05-0.20 \%$. In each case enzyme activity was increased in the presence of Triton X-100 compared with results obtained by assaying activity in its absence (table 1). GDH activity increased between $0.05 \%$ and $0.10 \%$ Triton $\mathrm{X}-100$ and showed a small further increase at $0 \cdot 15 \%$. Further increasing the concentration of Triton X-100 to $0.20 \%$ caused a decrease in enzyme activity. In subsequent experiments total GDH activity was assayed in the presence of $0.15 \%$ Triton X-100.

An aliquot $(0.05 \mathrm{ml})$ of the homogenate was removed for protein estimation and the remainder was used for measurement of total GDH activity. GDH activity was measured by following the oxidation of NADH fluorometrically. The initial reaction mixture, containing $45 \mathrm{mM}$ triethanolamine (pH 8.0), $105 \mathrm{mM}$ ammonium acetate, $2.6 \mathrm{mM}$ EDTA and $2.5 \mu \mathrm{M}$ rotenone was placed in a cuvette housed in a water jacket connected to a circulating water bath at $28^{\circ} \mathrm{C}$. After temperature equilibration, $50 \mu \mathrm{M}$ NADH, $1 \mathrm{mM}$ ADP and 15-30 $\mu \mathrm{l}$ of the leukocyte homogenate was added to the cuvette in a final volume of $2.0 \mathrm{ml}$. The samples were mixed and baseline NADH oxidation measured at an excitation wavelength of $340 \mathrm{nM}$ and an emission wavelength of 465 $\mathrm{nM}$. At this point a further $5 \mu \mathrm{l}$ of a $50 \mu \mathrm{M}$ NADH solution was added as a calibration standard and the decrease in fluorescence intensity was used to calculate subsequent NADH oxidation. When a stable baseline was obtained, GDH activity was initiated by the addition of a final concentration of $8 \mathrm{mM}$ sodium $\alpha$-ketoglutarate. The initial rate of increase in fluorescence intensity was used to calculate GDH induced NADH oxidation. All assays were carried out in duplicate.

Protein concentrations were determined utilising the technique of Lowry et al. ${ }^{19}$

(a) Stability of GDH during preparation of leukocyte pellets Since blood samples were collected from a variety of locations, pellet preparation was sometimes delayed for up to $2 \mathrm{~h}$. Consequently, in one experiment samples of whole blood $(5 \times 20 \mathrm{ml})$ from an individual were left in separate syringes at room temperature for periods of $1,2,3,4$ or $5 \mathrm{~h}$ following collection. Pellet preparation was then carried out as described above. GDH activity varied between 848-917 $\mathrm{nmol} / \mathrm{h} / \mathrm{mg}$ protein in these five samples, and did not change with time.

(b) Stability of GDH during storage of leukocyte pellet In one experiment, five samples of $20 \mathrm{ml}$ of blood were taken on the same occasion from one individual. Each sample was

Table 1 The effect of various final concentrations of Triton X-100 on total GDH activity in leukocyte pellets in four different control subjects

\begin{tabular}{lllll}
\hline & \multicolumn{4}{l}{ Total } \\
\hline & 1 & 2 & 3 & 4 \\
\hline $\begin{array}{l}\text { Subjects } \\
\text { Final concentration }\end{array}$ & & & & \\
$\quad$ of Triton X-100 & 117 & 139 & 108 & 109 \\
0 & 370 & 265 & - & 257 \\
$0 \cdot 05 \%$ & 730 & 901 & 569 & 553 \\
$0 \cdot 1 \%$ & 783 & 952 & 620 & 718 \\
$0 \cdot 15 \%$ & 656 & 911 & 543 & 570 \\
$0 \cdot 2 \%$ & & & & \\
\hline
\end{tabular}


processed to produce a leukocyte pellet. All samples were then stored at $-70^{\circ} \mathrm{C}$. At intervals (1 day and 2, 4, 6 and 9 months), individual pellets were assayed for GDH activity as described above. Activity did not decrease over this period but tended to increase with time (GDH activity $(\mathrm{nmol} / \mathrm{h} / \mathrm{mg}$ protein): 1 day, 734; 2 months, 747; 4 months, 753; 6 months, 880; 9 months 810).

(c) Reproducibility of estimations of total GDH activity To determine variations in GDH activity in leukocytes from an individual on different occasions, blood was taken from six subjects on two to six different occasions and the leukocyte pellets were assayed for GDH activity. Little variation was observed. Two separate samples were measured in all six subjects; the difference between the first and second values averaged $\pm 10.4 \%$ (range 4.6 to $15.6 \%$ ). Six different samples were studied in two subjects; on average the values differed from the means by $6.9 \%$ and $3.8 \%$ respectively.

(d) The effects of sex and age on GDH activity To determine sex and age effects on GDH activity, enzyme activities in the control subjects were analysed by analysis of variance. In 29 normal male subjects aged between 22-81 years and in
13 female subjects aged between 25-85 years, there was no correlation between GDH activity and age or sex.

2 Basic assay procedure for the determination of heat labile and stable forms of GDH

The determination of the heat labile and stable forms of GDH in leukocyte pellet preparations was carried out according to a modification of the technique of Plaitakis $e t$ al. ${ }^{10}$

Aliquots $(0.5 \mathrm{ml})$ of the leukocyte homogenates were transferred to capped plastic tubes and incubated at $47 \cdot 5^{\circ} \mathrm{C}$ in a water bath, with agitation. The remaining homogenate was used for estimation of total GDH activity as described above. The samples were removed from the water bath and briefly mixed every 10 minutes to overcome the problem of clotting factors (see below). After $\mathbf{6 0}$ minutes incubation the homogenates were removed and assayed for GDH activity. "Heat-stable" GDH was considered to be the activity found after 60 min incubation, whereas "heat-labile" GDH was the value obtained after subtracting the heat-stable from the total activity. Since Triton X-100 has been reported to alter the thermostability of $\mathrm{GDH},{ }^{10}$ in these experiments Triton

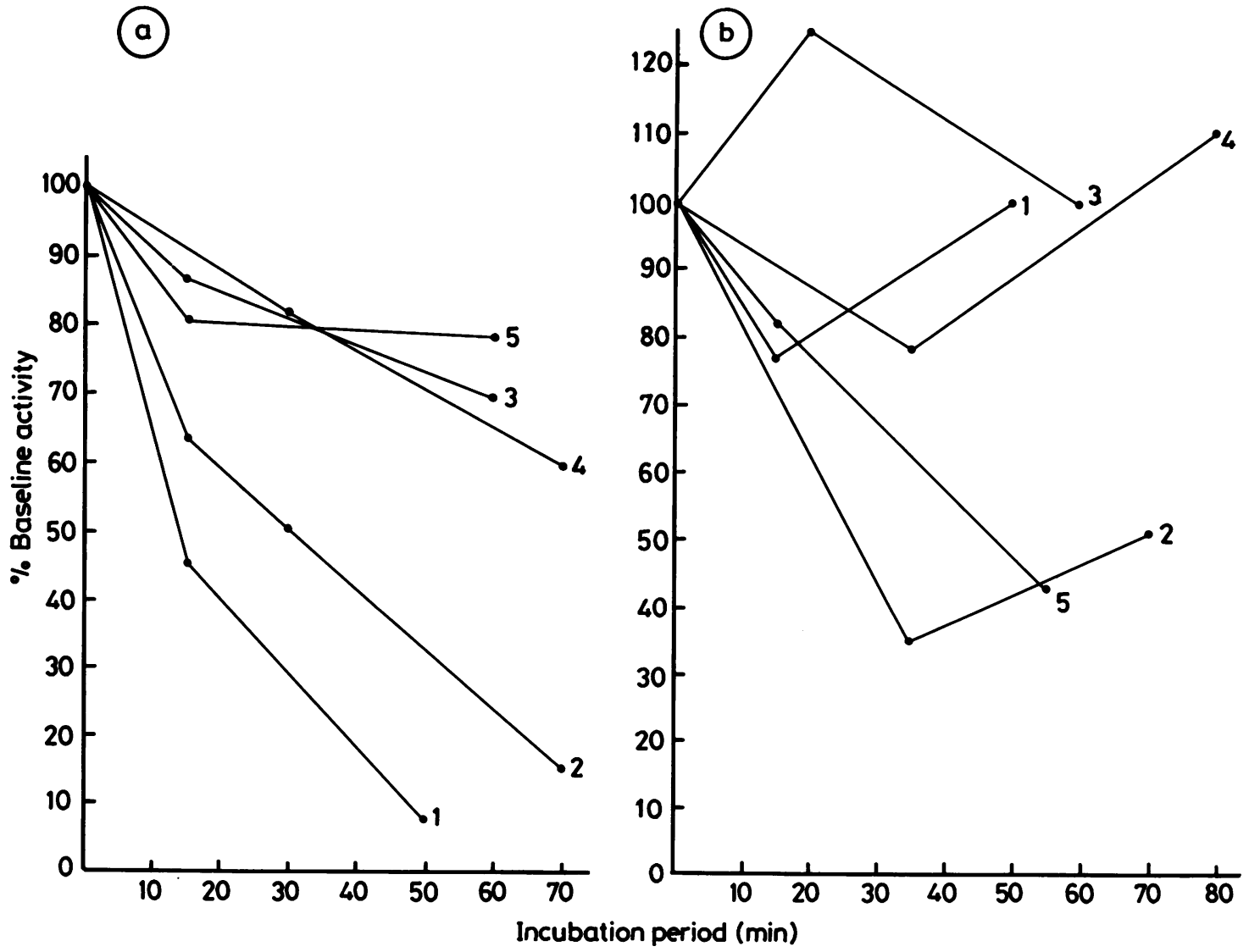

Fig 1 The effect of incubation of (a) particulate and (b) soluble fractions of leukocyte homogenates from five individuals at $47.5^{\circ} \mathrm{C}$ for up to $80 \mathrm{~min}$ on GDH activity. The results are expressed as a percent of baseline GDH activity measured in the fractions prior to the start of the incubations. 
(a)

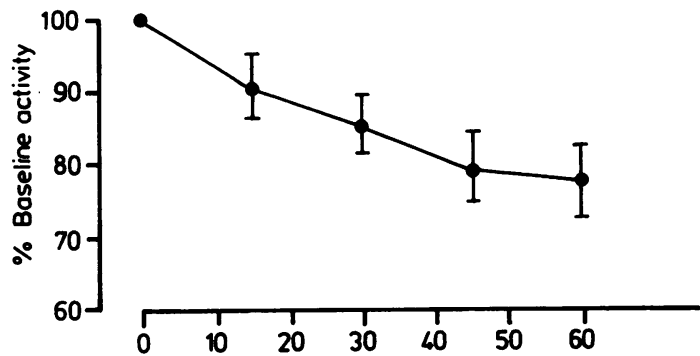

b)
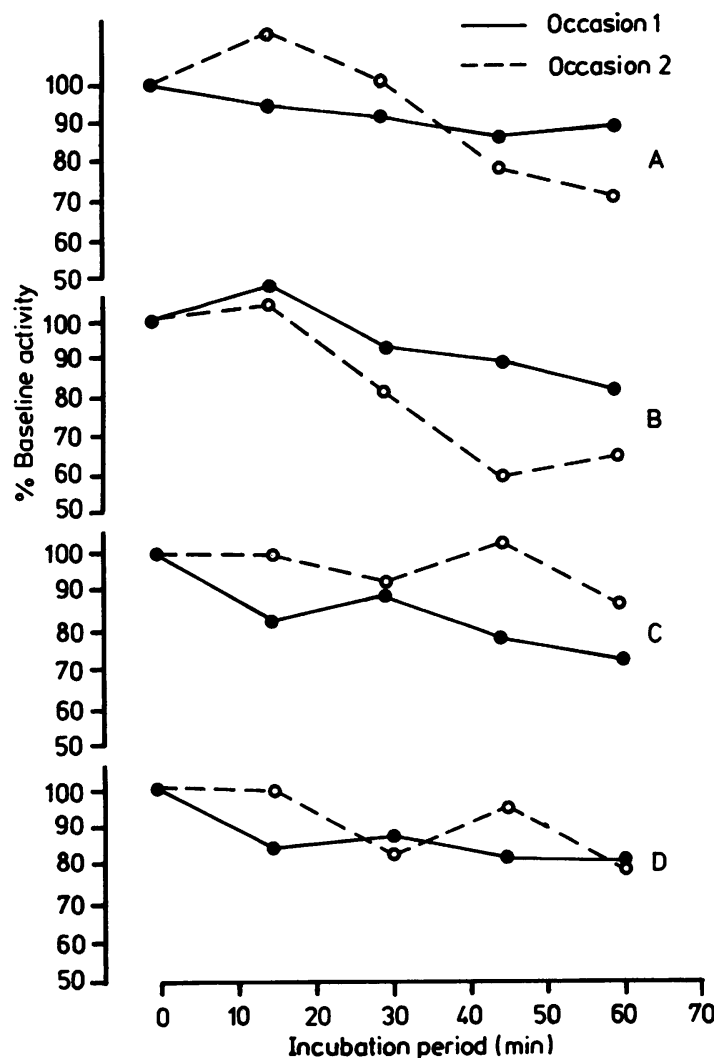

Fig 2 The effect of incubation of leukocyte homogenates at $47.5^{\circ} \mathrm{C}$ for up to $60 \mathrm{~min}$ on $\mathrm{GDH}$ activity. (a) The mean (1 SEM) effect of incubation of leukocyte homogenates from five individuals. (b) The effect of incubation of leukocyte homogenates from four individuals on two separate occasions. The results are expressed as a percent of baseline GDH activity in the homogenates prior to the start of the incubations.

X-100 was not added to the homogenate obtained from the leukocyte pellet, but was added to sample cuvettes to give a final optimal concentration of $0.075 \%$. However, we found no significant difference in total GDH activity determined by the addition of Triton X-100 either prior to or after incubation of the leukocyte homogenates. In leukocyte pellets from 19 individuals, GDH activity with $0 \cdot 15 \%$ Triton X-100 added prior to incubation was 748, SD 245 (mean, 1 SD) $\mathrm{nmol} / \mathrm{h} / \mathrm{mg}$ protein; with Triton $\mathrm{X}-100$ added to the same samples after incubation it was 762, SD $210 \mathrm{nmol} / \mathrm{h} / \mathrm{mg}$ protein.

In some experiments soluble ("heat stable GDH") and particulate ("heat labile GDH") fractions were separated according to Plaitakis et al. ${ }^{10}$ Subcellular fractionation revealed $36-82 \%$ (mean 70 , SD $7 \%$ ) of total GDH to be present in the soluble fraction; $10-25 \%$ (mean 20, SD 5\%) of total activity was found in the particulate fraction; $0-11 \%$ (mean $6 \%$ ) activity remained in the $480 \times g$ pellet. However, incubation of particulate fractions from five individuals at $47.5^{\circ} \mathrm{C}$ for up to $80 \mathrm{~min}$ caused a variable $20-90 \%$ loss of GDH activity (fig 1A). Similarly, incubation of soluble fractions at $47.5^{\circ} \mathrm{C}$ for up to 80 min resulted in marked variations in GDH activity ranging between a $25 \%$ increase to a $65 \%$ decrease in enzyme activity (fig 1B).

(a) Effect of incubation time and reproducibility of heat labile and heat stable estimates of GDH activity in whole leukocyte preparations Incubation of whole homogenates from five individuals at $47 \cdot 5^{\circ} \mathrm{C}$ for up to $60 \mathrm{~min}$ revealed $100-76 \%$ (mean $83 \%$ ) to be heat stable and $0-24 \%$ (mean $17 \%$ ) of total enzyme activity to be heat labile (fig $2 A$ ). In all cases the decrease in enzyme activity had reached a plateau by the end of the incubation period.

In another set of experiments whole homogenates were incubated for periods of up to $60 \mathrm{~min}$ in a shaking water bath. Samples from individual subjects were examined on two occasions. Again, the heat labile component varied between $9-29 \%$ (mean $21 \%$ ) of total enzyme activity (fig 2A). Enzyme sensitivity to heat varied within an individual on the two occasions studied (fig 2B).

In experiments where the homogenates from the leukocyte pellet of five individuals were divided into two or three aliquots, the heat labile component varied by $11-86 \%$ between individuals and varied up to twofold in the different aliquots from the same homogenates. Overall in these experiments, heat labile GDH activity was $23 \%$, and heat stable activity $77 \%$ of total homogenate activity.

(b) Attempts to overcome the problem of clotting factors affecting heat labile and stable GDH determinations Fibrous masses contaminated the samples following heat treatment. In an attempt to eliminate these, the following measures were taken. In some experiments homogenates were allowed to stand on ice for approximately $30 \mathrm{~min}$. Large fibrous masses sedimented and the supernatant was aspirated with a pipette for GDH determination. In other experiments, homogenates were incubated for $60 \mathrm{~min}$ at $47.5^{\circ} \mathrm{C}$ in a shaking water bath and vigorously mixed at 10 min intervals using a whirlmixer. Total activity was still lower compared with that of the heat stable component in a number of patients as the problem of clotting factors could not be completely eliminated.

\section{Patients and control subjects}

Total GDH activity was determined in 39 normal volunteers 
(mean age, 43, SD 18 years), and in 32 neurological controls with known diseases of muscle, the peripheral nervous system or spinal cord, clinically definite multiple sclerosis, or cerebrovascular disease (mean age 51, SD 15 years).

Total GDH activity was determined in four groups of patients with degenerative neurological diseases:

(1) Sixty-six patients with a variety of degenerative ataxic disorders (mean age 52, SD 16 years): (a) seven with early onset (before the age of 20) autosomal recessive ataxic disorders, six of whom had "early onset cerebellar ataxia with retained tendon reflexes" 20 and one Kjellin's syndrome; ${ }^{3}$ (b) four with autosomal recessive late onset (over the age of 20) cerebellar ataxia; (c) 19 (from 15 families) with autosomal dominant cerebellar ataxia; and (d) 36 with "idiopathic" late onset cerebellar ataxia. ${ }^{1}$ The mean age of onset of symptoms in groups b, c, and d was 44 years. Thirty-three of the 66 patients had progressive cerebellar ataxia without other physical signs apart from evidence of mild pyramidal tract involvement in some cases. In the other 33 cases cerebellar ataxia was combined with one or more associated features, such as peripheral neuropathy in 22 , supranuclear ophthalmoplegia in 11, dementia in eight, extrapyramidal involvement in seven, and autonomic failure in three. None had a predominant akinetic-rigid syndrome.

(2) Forty patients with Parkinson's disease (mean age 59, SD 14 years). All had a typical akinetic-rigid syndrome (with or without tremor) and an initial considerable response to levodopa or dopamine agonist therapy.

(3) Thirty-two patients with multiple system atrophy (mean age 61 , SD 8 years) who could be divided into two main categories: (a) nine with an akinetic-rigid syndrome unresponsive to levodopa or dopamine agonist therapy, five of whom had involvement of eye movements incompatible with a diagnosis of Parkinson's disease, three mild cerebellar ataxia, and three peripheral neuropathy; and (b) 23 with an akinetic-rigid syndrome associated with progressive autonomic failure, including nine with additional cerebellar signs, six with supranuclear ophthalmoplegia, and one with peripheral neuropathy. Cerebellar dysfunction was not the predominant clinical feature in any of these cases.

(4) Twenty patients with other movement disorders. These comprised: (a) eight patients with Steele-RichardsonOlszewski syndrome (progressive supranuclear palsy) (mean age 66, SD 6 years). All had a progressive akinetic-rigid syndrome, unresponsive to drug therapy, with a characteristic supranuclear gaze palsy involving vertical gaze, including downgaze; (b) eight patients with juvenile-onset (before the age of 21 years) Parkinsonism (mean age 31, SD 17 years); (c) four patients with an adult onset syndrome of dystonia followed by akinetic-rigid Parkinsonism, unresponsive to drug therapy (dystonia-Parkinsonism syndrome) (mean age 57, SD 6 years).

In total, 71 control subjects and 158 patients with ataxia or movement disorders were studied.

Control subjects or patients taking drugs known to affect GDH activity (such as steroids and non-steroidal antiinflammatory drugs) were not included. The definition of a low level of GDH activity is arbitrary. We have followed Duvoisin and Chokroverty ${ }^{9}$ in using the criterion of a value less than $50 \%$ of the mean level of activity in control subjects. When the level of GDH activity was found to be low, the assay was repeated.

To compare mean values for GDH activity in different subject groups, raw data for total GDH activity were logged and an analysis of variance was carried out followed by a two-tailed Student's $t$ test.

\section{Results}

Total GDH activity in patients and control subjects (table 2 and fig 3)

Mean (1 SD) total GDH activity in whole leukocyte preparations from the 39 normal controls was 789 , (200) $\mathrm{nmol} / \mathrm{h} / \mathrm{mg}$ protein (range 426-1184). Mean activity in the 32 neurological controls was 734 , (196) $\mathrm{nmol} / \mathrm{h} / \mathrm{mg}$ protein (range 437-1148). As there were no significant differences between these two groups, the normal and neurological controls were combined; mean GDH activity in these 71 control subjects was $765,(199) \mathrm{nmol} / \mathrm{h} / \mathrm{mg}$ protein.

Mean total GDH activity was significantly reduced in the groups of patients with degenerative ataxic disorders, Parkinson's disease, and multiple system atrophy when compared with the combined control group. Mean GDH activity also was low in patients with Steele-Richardson-Olszewski syndrome and juvenile Parkinsonism, although the numbers in these groups were small (table 2).

There was considerable overlap between values for total GDH activity in individual patients and control subjects (fig 3). In a total of 14 patients GDH activity

Table 2 Glutamate dehydrogenase activity in leukocyte homogenates in normal controls, neurological controls and patients with neurological disorders

\begin{tabular}{|c|c|c|}
\hline Disease category & $\begin{array}{l}\text { Mean GDH activity (SD) } \\
(\mathrm{nmol} / \mathrm{h} / \mathrm{mg} \text { protein) }\end{array}$ & $\begin{array}{l}\text { Percent of combined } \\
\text { control value }\end{array}$ \\
\hline $\begin{array}{l}\text { Normal controls }(n=39) \\
\text { Neurological controls }(n=32) \\
\text { Combined normal and neurological controls }(n=71) \\
\text { Ataxic disorders }(n=66) \\
\text { Parkinson's disease }(n=40) \\
\text { Multiple system atrophy }(n=32) \\
\text { Steele-Richardson-Olszewski syndrome }(n=8) \\
\text { Juvenile Parkinsonism }(n=8) \\
\text { Dystonia-Parkinsonism }(n=4)\end{array}$ & $\begin{array}{l}789,(200) \\
734,(196) \\
765,(199) \\
623,+(214) \\
650,+(216) \\
609,+(171) \\
548,+(126) \\
576, \$(222) \\
610,(184)\end{array}$ & $\begin{array}{l}81.4 \\
85.0 \\
79.6 \\
71.6 \\
75.3 \\
79.7\end{array}$ \\
\hline
\end{tabular}

${ }^{*} \mathrm{p}<0.001 ; \uparrow \mathrm{p}<0.01 ; \ddagger \mathrm{p}<0.02 ; \S \mathrm{p}<0.05$ (2 tailed $t$ test, comparing patients with combined control mean). 


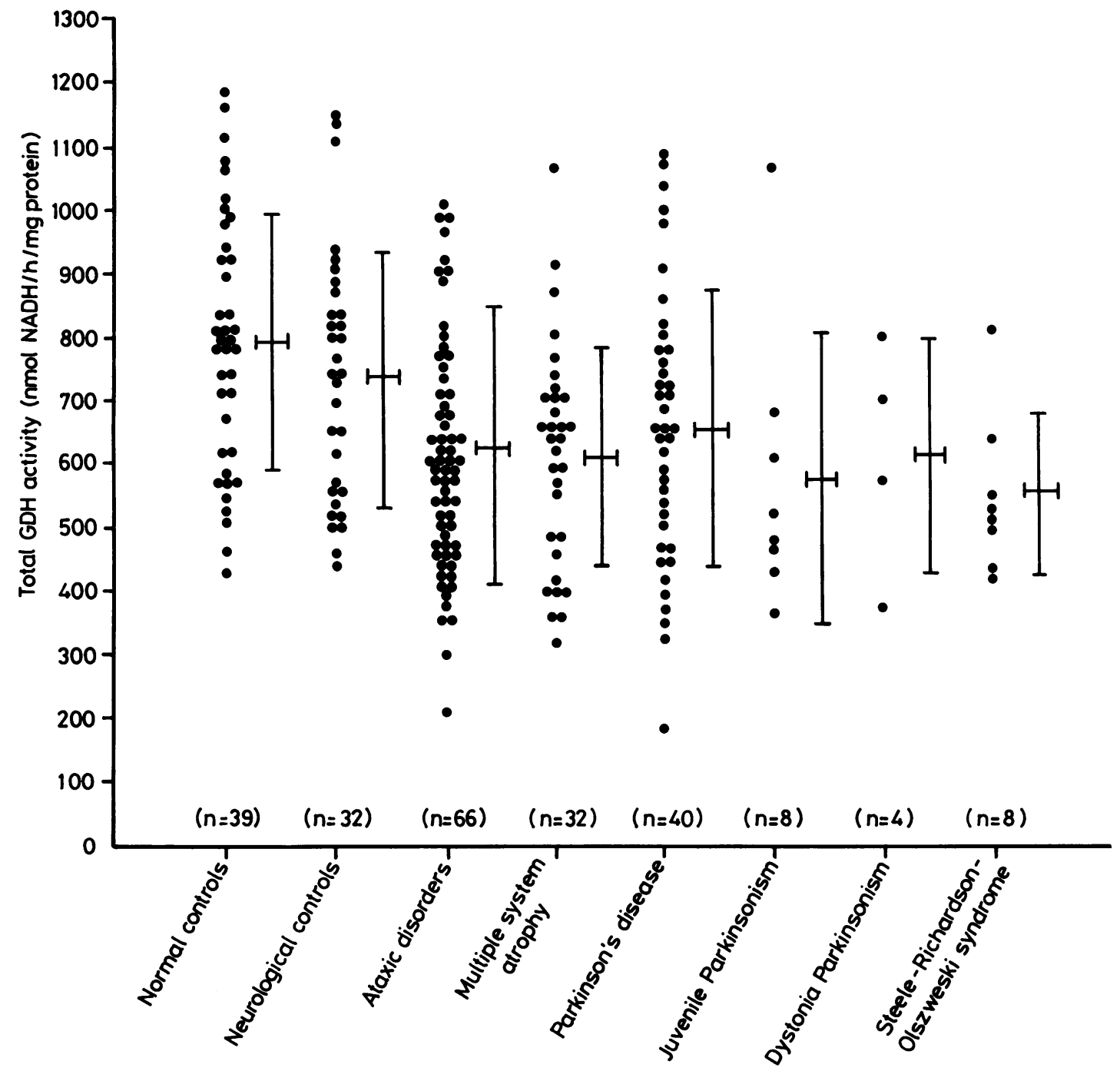

Fig 3 The distribution of total leukocyte GDH activity in normal and neurological controls and in patient groups with various degenerative neurological diseases. The bars indicate the group mean values (I SD). The data in the control groups and those with ataxic disorders, multiple system atrophy and Parkinson's disease groups were normally distributed about the mean as judged by the sign test $(p<0.01)$.

was less than $50 \%$ of the control mean (that is, less than $383 \mathrm{nmol} / \mathrm{h} / \mathrm{mg}$ protein). Nine of those 14 patients had total GDH activity values more than two standard deviations below the mean control values (that is, less than $363 \mathrm{nmol} / \mathrm{h} / \mathrm{mg}$ protein). Five patients had ataxic disorders, four Parkinson's disease, three multiple system atrophy, one juvenile Parkinsonism and one dystonia-Parkinsonism.
Clinical features of patients with GDH activity less than $50 \%$ of mean control value

1 Ataxic disorders

(1) A 57 year old male developed tremor of the head and hands when aged 44 years and had subsequently noticed progressive gait ataxia and memory loss. On examination he was dysarthric, demented, and 
emotionally labile with prominent titubation of the head. There was severe intention tremor in the upper limbs and marked gait ataxia; the tendon reflexes were increased and the plantar responses extensor. GDH activity was $300 \mathrm{nmol} / \mathrm{h} / \mathrm{mg}$ protein.

(2) A 54 year old female gave a history of progressive memory loss for 15 years and unsteadiness for 5 years. Examination showed moderate dementia, cerebellar dysarthria, and limb and gait ataxia with increased tendon reflexes and extensor plantar responses. GDH activity was $356 \mathrm{nmol} / \mathrm{h} / \mathrm{mg}$ protein.

(3) A 70 year old female developed progressive ataxia of gait at the age of 55 years. On examination she had nystagmus on lateral gaze, cerebellar dysarthria and mild limb ataxia, but marked unsteadiness on walking. The tendon reflexes were brisk apart from the ankle jerks which were absent; the plantar responses were flexor. GDH activity was 208 $\mathrm{nmol} / \mathrm{h} / \mathrm{mg}$ protein.

(4) An 83 year old male gave a 25 year history of progressive unsteadiness of gait. He had mild limb ataxia but more severe truncal ataxia. The tendon reflexes were brisk, but the plantar responses were flexor. GDH activity was $356 \mathrm{nmol} / \mathrm{h} / \mathrm{mg}$ protein.

(5) A 58 year old male developed increasing gait ataxia at the age of 48 years. He then developed a typical dystonic writer's cramp affecting the right hand. Four years after the onset, he noticed difficulty in moving his eyes voluntarily. Nine years after onset, he developed gross torticollis. A maternal aunt had torticollis, and his mother died young at the age of 42 ; one brother and one sister developed a similar illness to his. On examination he was intelligent, but had a severe complete ophthalmoplegia for voluntary and following movements in both the vertical and horizontal planes; eye movements were only slightly improved by the doll's-head manoeuvre. There was a severe torticollis with the chin deviated to the left, a dystonic writer's cramp of the right hand, and abnormal voice and cough suggesting a 10th nerve palsy, moderate ataxia of both arms, and marked ataxia of the legs and gait. The tendon reflexes were normal and the plantar responses flexor. GDH activity was $374 \mathrm{nmol} / \mathrm{h} / \mathrm{mg}$ protein.

\section{Parkinson's disease}

(6) A 34 year old female gave a 6 year history of increasing rigidity of the left arm and a 1 year history of dragging of the left leg on walking. On examination there was rigidity and bradykinesia of the left arm and leg. The tendon reflexes were normal and the plantar responses were flexor. There were no other abnormal neurological signs. She responded well to treatment with levodopa. GDH activity was $321 \mathrm{nmol} / \mathrm{h} / \mathrm{mg}$ protein.

(7) A 61 year old female developed Parkinsonism at the age of 39 , which progressed only slowly. She responded well to the introduction of levodopa but some years later developed a typical wearing-off effect. Examination revealed signs only of severe generalised akinetic-rigid Parkinsonism when off, changing to mobility with generalised dyskinesias when on treatment. GDH activity was $181 \mathrm{nmol} / \mathrm{h} / \mathrm{mg}$ protein.

(8) A 70 year old female had developed rest tremor of the left arm 17 years previously. It spread to involve all four limbs and she became progressively disabled by increasing stiffness and akinesia. On examination she had signs of typical Parkinson's disease with classical rest tremor of all four limbs, and a moderate generalised akinetic-rigid syndrome. There were no other abnormal neurological signs. There was difficulty stabilising her on levodopa treatment, because of nausea and vomiting, but eventually she tolerated an adequate dose with considerable improvement. GDH activity was $349 \mathrm{nmol} / \mathrm{h} / \mathrm{mg}$ protein.

(9) A 53 year old male developed dragging of the left leg when he was aged 28 years. Subsequently he gradually became stiff and slow. Levodopa treatment produced modest improvement. On examination he had severe generalised akinetic-rigid Parkinsonism with mild postural tremor of the hands. Voluntary eye movements were slow, but full in range. The reflexes were brisk and the plantar responses were flexor. There was mild postural hypotension but no other evidence of autonomic neuropathy. GDH activity was $364 \mathrm{nmol} / \mathrm{h} / \mathrm{mg}$ protein.

\section{Multiple system atrophy}

(10) A 43 year old male complained of increasing difficulties with speech, gait and tremor for at least the previous 10 years. On examination he had typical signs of Parkinsonism with tremor of the jaw and tongue, and rest tremor of all four limbs. There was generalised bradykinesia and rigidity, and an abnormal shuffling gait. Voluntary and following eye movements were abnormal with slow saccades in all directions of gaze, and optokinetic nystagmus was absent. Reflexes were normal; the right plantar was extensor but the left flexor. Sensation was normal. Despite the normal tendon reflexes, there was evidence of a peripheral neuropathy in the legs on nerve conduction studies. GDH activity was $319 \mathrm{nmol} / \mathrm{h} / \mathrm{mg}$ protein.

(11) A 57 year old male had developed increasing tremor of the left hand seven years previously and dragging of the right leg two years previously. On examination he had signs of typical right hemiParkinsonism, with similar much milder signs on the left. He had had a good response to treatment with bromocriptine, but subsequently developed 
impotence, postural hypotension, and urinary incontinence. Investigation showed evidence of autonomic neuropathy. GDH activity was $361 \mathrm{nmol} / \mathrm{h} / \mathrm{mg}$ protein.

(12) A 54 year old male developed erectile impotence at the age of 47 , followed some months later by tremor, sialorrhoea, slurring of speech, nocturnal respiratory stridor, difficulty in walking, hesitancy of micturition and urinary incontinence. On examination he had impassive facies, mild cogwheel rigidity in the limbs, bradykinesia, a festinant gait, and mild impairment of cardiovascular reflexes. GDH activity was $366 \mathrm{nmol} / \mathrm{h} / \mathrm{mg}$ protein.

\section{Juvenile Parkinsonism}

(13) A 49 year old male developed shaking of the head and then the left leg at the age of 17 years. The tremor became increasingly severe and he developed stiffness of his left limbs, spreading to the right. Two sisters and one brother had the same condition, all with onset in late adolescence. On examination he had predominantly left sided Parkinsonism with severe rest tremor of the arm and leg, and rigidity with bradykinesia. Eye movements were normal, tendon reflexes were normal, and plantar responses were flexor. He had only a modest response to levodopa. GDH activity was $365 \mathrm{nmol} / \mathrm{h} / \mathrm{mg}$ protein.
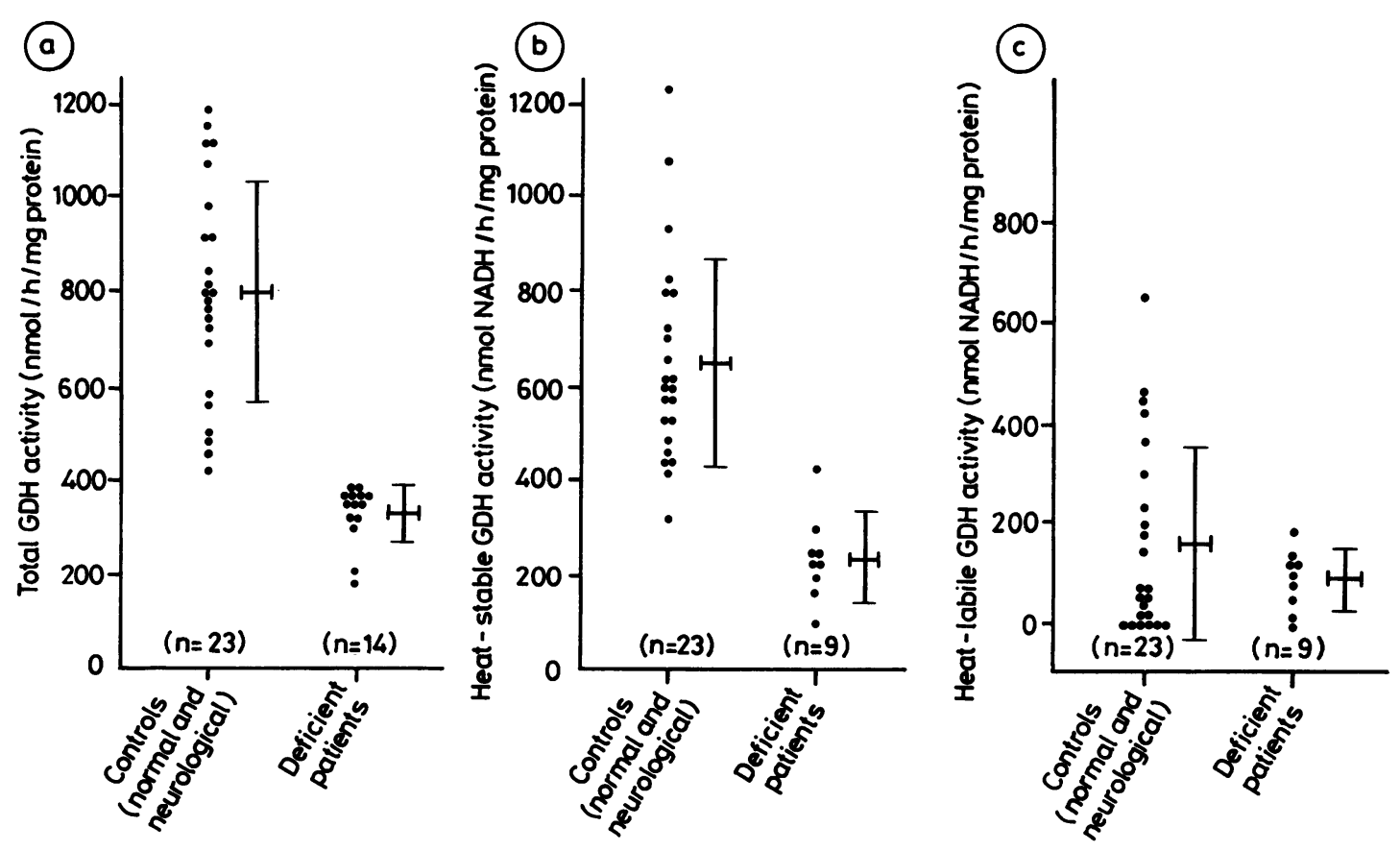

Fig 4 The distribution of (a) total, (b) heat stable and (c) heat labile GDH activity in leukocyte homogenates from normal and neurological controls compared to patients with total GDH activity less than 50\% of the control mean. The bars indicate the mean group values (1 SD).

\section{Dystonia-Parkinsonism}

(14) A 64 year old male gave a 20 year history of increasing difficulty with walking due to dragging of his left leg and hyperextension of the back and neck muscles. Fourteen years previously he had developed a rest tremor of the left arm, followed soon after by rapid wasting and weakness. On examination he had dystonic retrocollis and extensor spasms of the back, particularly on walking, and dystonic posturing of the left leg. There was a rest tremor of the left arm and akinesia of the left arm and leg, but no rigidity. There was wasting and weakness around the left shoulder and upper arm, with absent tendon jerks in the left arm. The ankle jerks were absent but the plantar responses were flexor; appreciation of vibration was reduced slightly at the ankle. He had been a boxer in the past, and a CT scan showed the presence of a cavum septum pellucidum. Cervical spine radiographs showed marked spondylosis. Nerve conduction studies showed absent sural nerve sensory action potentials, but motor conduction velocity in the legs was normal. GDH activity was $373 \mathrm{nmol} / \mathrm{h} / \mathrm{mg}$ protein.

Heat labile and heat stable GDH activity in patients with low total GDH values (fig 4)

In nine normal control subjects total GDH activity 
was 813,284 (mean, $1 \mathrm{SD}$ ) $\mathrm{nmol} / \mathrm{h} / \mathrm{mg}$ protein, of which $673,284 \mathrm{nmol} / \mathrm{h} / \mathrm{mg}$ protein was heat stable and $162,236 \mathrm{nmol} / \mathrm{h} / \mathrm{mg}$ protein was heat labile. Similarly, in 14 neurological control subjects total GDH activity was $791,200 \mathrm{nmol} / \mathrm{h} / \mathrm{mg}$ protein of which heat stable represented $638,173 \mathrm{nmol} / \mathrm{h} / \mathrm{mg}$ protein and heat labile $161,168 \mathrm{nmol} / \mathrm{h} / \mathrm{mg}$ protein. In the combined control group the heat labile fraction represented approximately $20 \%$ of total GDH activity.

In 14 GDH deficient patients total GDH activity was $328,61 \mathrm{nmol} / \mathrm{h} / \mathrm{mg}$ protein. Heat stable and heat labile components were determined in nine of these 14 patients. The heat stable fraction was 239, $91 \mathrm{nmol} / \mathrm{h} / \mathrm{mg}$ protein, and the heat labile fraction 89 , $61 \mathrm{nmol} / \mathrm{h} / \mathrm{mg}$ protein. The heat labile fraction represented $27 \%$ of total GDH activity.

\section{Discussion}

Although 14 of the 158 patients with degenerative neurological disorders investigated in this study had reduced total GDH activity, as defined by Duvoisin and Chokroverty, ${ }^{9}$ their clinical features were very variable. Four of them had typical Parkinson's disease, and GDH deficiency has not been reported previously in such cases.

There is no reason to suggest that the population of patients investigated here can be distinguished on nosological grounds from those studied by other authors. The GDH deficient cases described to date comprise a subgroup of patients stated to have OPCA; we have avoided the use of the term OPCA in this study as clinical criteria for diagnosis are controversial. ${ }^{21,} 22$

A large proportion of our patients with either degenerative ataxic disorders or multiple system atrophy were clinically similar to those with necropsyproven cases of OPCA reviewed by Berciano. ${ }^{4}$ OPCA nearly always presents in adult life. Of our 59 adultonset ataxic patients, 31 (53\%) had additional clinical features (peripheral neuropathy, supranuclear ophthalmoplegia, or Parkinsonism) commonly described in cases of OPCA. Sixteen $(50 \%)$ of the patients with multiple system atrophy had significant ataxia, supranuclear ophthalmoplegia, or peripheral neuropathy.

Twenty-six patients with GDH deficiency have been described in sufficient detail to analyse their clinical features. $^{6,8,10-13}$ All had cerebellar ataxia and/or Parkinsonism and in $18(69 \%)$ there was supranuclear ophthalmoplegia and/or peripheral neuropathy; all four features were present in six, and three occurred in a further six. In the present series of 98 patients with degenerative ataxic disorders or multiple system atrophy, close to $50 \%$ had similar additional clinical features.

Amongst the 98 patients with ataxia or multiple system atrophy, eight $(8 \%)$ were found to have GDH values below $50 \%$ of the control mean. However, four of $40(10 \%)$ patients with Parkinson's disease had low GDH activity, and we also found low GDH activity in single patients with juvenile Parkinsonism and the dystonia-Parkinsonism syndrome. Low levels of GDH activity cannot therefore be considered to be disease specific. Nor could we confirm a selective reduction of the heat labile fraction of GDH in those with low total activity.

Inspection of fig 3, which illustrates GDH activity in the control subjects and different patient groups, suggests a normal distribution of values amongst those with ataxia, multiple system atrophy and Parkinson's disease. An arbitrary definition of a low GDH value as less than $50 \%$ of the control mean inevitably leads to some patients being classified as GDH deficient. There is no suggestion of a bimodal distribution of GDH values in any of the diseases studied. We are forced to conclude that so-called GDH deficiency is not a marker of a specific disease entity, but merely represents the lower end of a normal distribution of leukocyte GDH activity.

Nevertheless, the averaged values for leukocyte GDH activity were lower in most patient groups, and this observation requires explanation. The patients with ataxia, multiple system atrophy and Parkinson's disease tended to be older than the controls, to be more physically disabled, and to be taking more drugs. Any or all of these factors may be responsible.

We thank physicians at the National Hospital for Nervous Diseases, in particular Sir Roger Bannister, and elsewhere for permission to study their patients, and the MRC for financial support.

\section{References}

1 Harding AE. "Idiopathic" late onset cerebellar ataxia. A clinical and genetic study of 36 cases. J Neurol Sci 1981;51:259-71.

2 Harding AE. The clinical features and classification of the late onset autosomal dominant cerebellar ataxias: A study of eleven families, including descendants of the "Drew family of Walworth". Brain 1982;105:1-28.

3 Harding AE. The hereditary ataxias and related disorders. Edinburgh, Churchill Livingstone, 1984.

4 Berciano J. Olivopontocerebellar atrophy. A review of 117 cases. J Neurol Sci 1982;53:253-72.

5 Koeppen AH, Barron KD. The neuropathology of olivopontocerebellar atrophy. In: The olivopontocerebellar atrophies. (Duvoisin RC, Plaitakis A, eds). Adv Neurol 1984;41:13-38.

6 Plaitakis A, Nicklas WJ, Desnick RJ. Glutamate dehydrogenase deficiency in three patients with spino-cerebellar syndromes. Ann Neurol 1980;7:297-303.

7 Yamaguchi T, Hayashi K, Murakami H, Maruyama S. Glutamate dehydrogenase deficiency in spinocerebellar degenerations. Neurochem Res 1982;7:627-36.

8 Duvoisin RC, Chokroverty S, Lepore F, Nicklas WJ. Glutamate dehydrogenase deficiency in patients with olivopontocerebellar atrophy. Neurology 1983;33:1322-6. 
9 Duvoisin RC, Chokroverty S. Clinical expression of glutamate dehydrogenase deficiency. In: Duvoisin RC, Plaitakis A, eds. The olivopontocerebellar atrophies. Adv Neurol 1984;41: 267-79.

10 Plaitakis A, Berl S, Yahr MD. Neurological disorders associated with deficiency of glutamate dehydrogenase. Ann Neurol 1984; 15:144-53.

11 Sorbi S, Piacentini S, Marini P, et al. Clinical pathology of recessive and dominant olivopontocerebellar atrophy. Observations on glutamate dehydrogenase activity. Ital J Neurol Sci 1984;2: Suppl 4:74-8.

12 Sorbi S, Tonini S, Giannini E, Piacentini S, Marini P, Amaducci L. Aonormal platelet glutamate dehydrogenase activity and activation in dominant and nondominant olivopontocerebellar atrophy. Ann Neurol 1986;19:239-45.

13 Chokroverty S, Duvoisin RC, Sachdeo R, Sage J, Lepore FE, Nicklas W. Neurophysiological study of olivopontocerebellar atrophy with or without glutamate dehydrogenase deficiency. Neurology 1985;35:652-9.

14 Konagaya Y, Konagaya A, Takayanagi T. Glutamate dehydrogenase and its isoenzyme activity in olivopontocerebellar atrophy. J Neurol Sci 1986;74:231-6.

15 Plaitakis A. Abnormal metabolism of neuroexcitatory amino acids in olivopontocerebellar atrophy. In: Duvoisin RC,
Plaitakis A, eds. The Olivopontocerebellar Atrophies. Adv Neurol 1984;41:225-43.

16 Plaitakis A, Berl S, Yahr MD. Abnormal glutamate metabolism in an adult-onset degenerative neurological disorder. Science 1982;216:193-6.

17 Finocchiaro G, Taroni F, Pandolfo M, Di Donato A. Glutamate metabolism alterations in dominant OPCA. Ital J Neurol Sci 1984;2: Suppl 4:134-40.

18 Olney JW. Neurotoxicity of excitatory amino acids. In: McGeer EG, Olney JW, McGeer PL, eds. Kainic Acid as a Tool in Neurobiology. New York, Raven Press, 1978;95-122.

19 Lowry HO, Rosebrough NJ, Lewis Farr A, Randall RJ. Protein measurement with the Folin phenol reagent. J Biol Chem 1951;277:467-74.

20 Harding AE. Early onset cerebellar ataxia with retained tendon reflexes: a clinical and genetic study of a disorder distinct from Friedreich's ataxia. J Neurol Neurosurg Psychiatry 1981;44: 503-8.

21 Duvoisin RC. The olivopontocerebellar atrophies. In: Marsden CD, Fahn S, eds. Movement Disorders-2. London, Butterworths, 1987;249-69.

22 Harding AE. Commentary: Olivopontocerebellar atrophy is not a useful concept. In: Marsden CD, Fahn S, eds. Movement Disorders-2. London, Butterworths, 1987;269-71. 